\title{
Sec62 promotes stemness and chemoresistance of human colorectal cancer through activating Wnt/ $\beta$-catenin pathway
}

Xiaofeng Liư ${ }^{1 *}$, Kunqi Su², Xiaoyan Sun ${ }^{2}$, Yang Jiang ${ }^{2}$, Lijun Wang ${ }^{1}$, Chenyu Hu' ${ }^{1}$, Chunfeng Zhang ${ }^{3}$, Min Lư Xiaojuan Du ${ }^{2^{*}}$ and Baocai Xing ${ }^{1 *}$

\begin{abstract}
Background: Cancer stem cell (CSC)-related chemoresistance leads to poor outcome of the patients with colorectal cancer (CRC). In this study, we identified the chemoresistance-relevant molecules and decipher the involved mechanisms to provide potential therapeutic target for CRC. We focused on Sec62, a novel target with significantly increased expression in chemoresistant CRC tissues, and further investigated its role in the progression of CRC.

Methods: Through analyzing the differentially-expressed genes between chemoresistant and chemosensitive CRCs, we selected Sec62 as a novel chemoresistance-related target in CRC. The expression and clinical significance of Sec62 were determined by immunoblotting and immunohistochemistry in tissues and cell lines of CRC. The roles of Sec62 in drug resistance, stemness and tumorigenesis were evaluated in vitro and in vivo using functional experiments. GST pull-down, western blot, coimmunoprecipitation and Me-RIP assays were performed to further explore the downstream molecular mechanisms.

Results: Sec62 upregulation was associated with the chemoresistance of CRC and poor outcome of CRC patients. Depletion of Sec62 sensitized CRC cells to chemotherapeutic drugs. Sec62 promoted the stemness of CRC cells through activating Wnt/ $\beta$-catenin signaling. Mechanistically, Sec62 bound to $\beta$-catenin and inhibited the degradation of $\beta$-catenin. Sec62 competitively disrupted the interaction between $\beta$-catenin and APC to inhibit the $\beta$-catenin destruction complex assembly. Moreover, Sec62 expression was upregulated by the $\mathrm{m}^{6} \mathrm{~A}$-mediated stabilization of Sec62 mRNA.

Conclusions: Sec62 upregulated by the METTL3-mediated $\mathrm{m}^{6} \mathrm{~A}$ modification promotes the stemness and chemoresistance of CRC by binding to $\beta$-catenin and enhancing Wnt signalling. Thus, $\mathrm{m}^{6} \mathrm{~A}$ modification-Sec62- $\beta$ catenin molecular axis might act as therapeutic targets in improving treatment of CRC.
\end{abstract}

Keywords: Sec62, Chemosensitivity, Cancer stem cell, CRC, Wnt/B-catenin signaling, $\mathrm{m}^{6} \mathrm{~A}$ modification

\footnotetext{
* Correspondence: liuxiaofeng100@bjmu.edu.cn;

duxiaojuan100@bjmu.edu.cn; xingbaocai88@sina.com

${ }^{1}$ Hepatopancreatobiliary Surgery Department I, Key laboratory of

Carcinogenesis and Translational Research (Ministry of Education/Beijing),

Peking University Cancer Hospital \& Institute, Beijing 100142, China

${ }^{2}$ Department of Cell Biology, School of Basic Medical Sciences, Peking

University Health Science Center, Beijing 100191, China

Full list of author information is available at the end of the article
}

C C The Author(s). 2021 Open Access This article is licensed under a Creative Commons Attribution 4.0 International License, which permits use, sharing, adaptation, distribution and reproduction in any medium or format, as long as you give appropriate credit to the original author(s) and the source, provide a link to the Creative Commons licence, and indicate if changes were made. The images or other third party material in this article are included in the article's Creative Commons licence, unless indicated otherwise in a credit line to the material. If material is not included in the article's Creative Commons licence and your intended use is not permitted by statutory regulation or exceeds the permitted use, you will need to obtain permission directly from the copyright holder. To view a copy of this licence, visit http://creativecommons.org/licenses/by/4.0/ The Creative Commons Public Domain Dedication waiver (http://creativecommons.org/publicdomain/zero/1.0/) applies to the data made available in this article, unless otherwise stated in a credit line to the data. 


\section{Background}

Colorectal cancer (CRC) is the fourth leading cause of cancer-related mortality [1]. Surgery is the cornerstone of treatment for CRC while adjuvant chemotherapy is routinely applied to improve the prognosis of the patients [2]. However, chemoresistance is one of the major problems hindering the CRC treatment [3]. Since the existence of cancer stem cells (CSCs) leads to chemotherapy failure and tumor recurrence, targeting the CSCs could improve the therapeutic effectiveness in CRC [46]. Thus, exploration of molecules controlling the stemness of CRC will provide therapeutic targets for CRC.

Wnt $/ \beta$-catenin signaling plays crucial roles in the maintenance of CSCs [7]. The turnover of $\beta$-catenin is the critical event in $\mathrm{Wnt} / \beta$-catenin signaling pathway [8]. Accumulated $\beta$-catenin enters the nucleus and binds to TCF transcription factors to activate the transcription of downstream genes including CD44, MYC and LGR5, which potentiate the stemness of CRC and promotes CRC progression [9-11]. Degradation of $\beta$-catenin is mediated by the $\beta$-catenin destruction complex, in which APC plays critical roles as it binds to AXIN1 and $\beta$ catenin [12]. In the majority (about 75\%) of CRC, $A P C$ gene is mutated and produces the $\mathrm{N}$-terminal truncated APC lacking of APC-AXIN1 interaction. Thus, the regulation of the APC- $\beta$-catenin interaction is critical in the activation of $\beta$-catenin in the CRC cells $[13,14]$. However, the mechanisms by which the APC- $\beta$-catenin interaction is regulated in CRC are not fully understood.

Here, we screened the chemosensitivity-related genes and identified Sec62 as a chemoresistant target. Sec62 was originally found to locate in the membrane of endoplasmic reticulum (ER) [15]. Recent studies have uncovered that Sec62 is upregulated in various human cancers [16-18]. However, it's unknown whether and how Sec62 acts in the CRC tumorigenesis and progression.

In the present study, we firstly evaluated the effect of Sec62 on the chemosensitivity and stemness of CRC. We further demonstrated that Sec62 activates $\beta$-catenin signaling to potentiate the stemness and attenuate the chemosensitivity in CRC. Additionally, Sec62 is upregulated by the METTL3-mediated $\mathrm{m}^{6} \mathrm{~A}$ modification of Sec62 mRNA in CRC.

\section{Materials and methods}

\section{Cell culture, antibodies and reagents}

CRC cell lines were obtained from the Cell Resource Center (National Infrastructure of Cell Line Resource, NSTI) and cultured in DMEM or RPMI 1640 medium. All medium were supplemented with $10 \%$ fetal bovine serum. Cells were maintained in $5 \% \mathrm{CO}_{2}$ at $37^{\circ} \mathrm{C}$ in incubators with $100 \%$ humidity. Cell line authentications were performed by the provider. The antibodies and reagents for this study are listed in supplementary Table S1.

\section{Patient samples and tissue microarrays}

Tissue microarrays consist of 102 formalin-fixed, paraffin-embedded CRC tissues and non-tumorous colorectal tissues obtained from the CRC patients who underwent curative surgical resection without prior neoadjuvant therapy from January 2004 to December 2008 in Peking University Cancer Hospital. The clinical pathologic characteristics of patients including age, gender, tumor location, carcinoembryonic antigen (CEA) level, tumor size, clinical stage, and distant metastasis are summarized in Supplemental Table S2.

\section{Cell transfection}

Cells were transfected with plasmid DNA or siRNA RNA duplexes by Lipofectamine 2000 (Invitrogen) according to the manufacturer's protocol. In transient transfection experiments, plasmid DNA was kept constant with empty vector. shRNAs were delivered by lentiviral infection with lentiviruses produced by transfection of HEK293T cells with the vector pLKO.1. Cells infected with lentiviruses delivering scrambled shRNA (shCtrl) were used as negative control cells. Short interfering RNA (siRNA) sequences were directly synthesized (GenePharma, Shanghai, China). The sequences of shRNAs and siRNAs are listed in the Table S3.

\section{Sphere formation assay}

For sphere formation assay, a total of 800 cells were suspended in a serum-free medium and were plated into an ultralow attachment plate. Then, the cells were cultured in DMEM/F12 medium (Invitrogen) supplemented with insulin (Sigma), B27 (GIBCO), EGF (Sigma) and basic FGF (Sigma). For the serial passaging, the primary spheres were collected and resuspended in DMEM/F12 medium with the above supplements after trypsin dissociation. Finally, the number of spheres was counted under microscope and the size of spheres was estimated using Image J software.

\section{MTT assay and colony formation}

For MTT assay, cells were seeded in a 96-well plate and cultured with indicated drugs for $72 \mathrm{~h}$. Then, MTT assay was employed to assess cell viability according to the manufacturer's protocol (Promega). For colony formation, cells were treated with DMSO or chemotherapeutic agents for $24 \mathrm{~h}$, and subsequently seeded into 6-well plate (500 cell per well). After cultured for 12 days, the colonies were fixed with $4 \%$ paraformaldehyde and stained with $0.5 \%$ crystal violet. The visible colonies were counted and summarized. 


\section{Flow cytometric analysis}

Apoptosis assay was performed using Annexin V-FITC and propidium iodide staining kit (Keygen, Nanjing, China) according to the manufacturer's protocol. To detect $\mathrm{CD} 133^{+} / \mathrm{CD}_{4} 4^{+}$cells, CD133-PE (\#130-090-853) and CD44-APC (\#130-098-110) antibodies (Miltenyi Biotec.) were utilized to label cells. Then, labelled cells were subjected to flow cytometric analyses.

\section{In vivo chemo-resistance assay}

DLD-1 cells were subcutaneously implanted into 4-6 weeks old female nude mice. When tumors reached a size of about $50 \mathrm{~mm}^{3}$, the nude mice were randomly divided into 6 groups. Group 1, 3 and 5 received an intratumoral injection of lentivirial-ctrl shRNA once per week for 5 weeks. Group 2, 4 and 6 received an intratumoral injection of lentivirial-Sec62 shRNA once per week for 5 weeks. At the same time, group 3 and 4 received an additional intraperitoneal injection of 5 - Fu $(0.15 \mathrm{mg} / \mathrm{kg})$ twice per week for 4 weeks. Group 5 and 6 received an additional intraperitoneal injection of oxaliplatin $(30 \mathrm{mg} / \mathrm{kg})$ twice per week for 5 weeks. The tumor size was measured every 5 days and tumor volume was calculated using the formula $\mathrm{V}=0.5 \times \mathrm{W}^{2} \times \mathrm{L}(\mathrm{V}$, volume; L, Length; W, Width).

\section{Coimmunoprecipitation assay}

Cells were harvested and cell lysates were prepared in Buffer A $(25 \mathrm{mM}$ Tris-Cl pH 7.5, $150 \mathrm{mM} \mathrm{KCl,} 1 \mathrm{mM}$ DTT, 2 mM EDTA, 0.5 mM PMSF, and 0.2\% Nonidet P40) and used for immunoprecipitation. The indicated antibodies were coupled with a $50 \%$ suspension of protein A-Sepharose beads (GE Healthcare) in Buffer IPP500 (500 mM NaCl, $10 \mathrm{mM}$ Tris-Cl pH 8.0, $0.2 \%$ Nonidet P-40). Coupled beads were incubated with cell lysates for $2 \mathrm{~h}$ at $4{ }^{\circ} \mathrm{C}$. After washing, the precipitates were examined by Western blot using the indicated antibodies.

\section{RNA immunoprecipitation (RIP)}

RIP assay was carried out as previously described [19, 20]. Briefly, cells were treated with UV irradiation and lysed in high salt lysis buffer. Then, magnetic beads coated with $5 \mu \mathrm{g}$ of antibodies were incubated with the prepared cell lysates overnight at $4{ }^{\circ} \mathrm{C}$. The RNA-protein complexes were washed for 6 times and incubated with proteinase $\mathrm{K}$ digestion buffer. RNA was extracted by phenol-chloroform RNA extraction methods. The relative expression of RNA was determined by RT-qPCR and normalized to the input.

\section{In vivo limiting dilution assay}

To investigate the effect of Sec62 on tumor self-renewal, an in vivo limiting dilution assay was performed. Female
$\mathrm{BABL} / \mathrm{c}$ nude mice ( 4 to 5 weeks old) were randomly divided into 4 groups (5 mice per group). Sec62knockdown or control DLD1 cells were injected subcutaneously in the flank with a serial dilution of cells. At the end of 80 days, the tumor incidence of each group was observed and the stem cell frequency was estimated using an online tool at http://bioinf.wehi.edu.au/ software/elda.

\section{Me-RIP ( $m^{6}$ A-RNA immunoprecipitation) assay}

Me-RIP assay was performed following published protocols $[20,21]$. Briefly, Poly (A) mRNAs were isolated from total RNA with poly-T oligo attached magnetic beads (Promega). The cleaved RNA fragments were incubated for $2 \mathrm{~h}$ at $4{ }^{\circ} \mathrm{C}$ with $\mathrm{m}^{6} \mathrm{~A}$-specific antibody (No. 202003, Synaptic Systems, Germany) in IP buffer ( $50 \mathrm{mM}$ Tris$\mathrm{HCl}, 750 \mathrm{mM} \mathrm{NaCl}$ and $0.5 \%$ Igepal CA-630) supplemented with BSA. The mixture was then incubated with protein-A beads and eluted with elution buffer $(1 \times \mathrm{IP}$ buffer and $6.7 \mathrm{mM} \mathrm{m}^{6} \mathrm{~A}$ ). Eluted RNA was precipitated by $75 \%$ ethanol. RNA was finally extracted by phenolchloroform RNA extraction methods. The relative expression of RNA was assessed by qPCR and normalized to the input.

\section{Immunohistochemistry}

Tissue sections were deparaffinized in xylene and rehydrated in ethanol. Then, the sections were treated with peroxidase solution and citrate buffer. After treatment with blocking buffer, sections were incubated with a primary antibody at $4{ }^{\circ} \mathrm{C}$ overnight. Next, the sections were visualized using an UltraVision Quanto Detection System HRP DAB Kit (ZSGB-Bio, China) according to the manufacturer's protocols. The staining intensity were evaluated independently by two observers blinded to the clinical outcome. The percentages of positive tumor cells were scored as follows: $1 \%, 0$ points; $1-25 \%, 1$ point; 26-50\%, 2 points; $51-75 \%, 3$ points; and $75 \%$, 4 points. The staining intensity was scored as follows: no staining, 0 points; weak staining, 1 point; moderate staining, 2 points; and strong staining, 3 points. Then, the two scores were multiplied to acquire a combined score ranging from 0 to 12 .

\section{Immunofluorescence staining}

Cells were fixed with $4 \%$ paraformaldehyde for $15 \mathrm{~min}$ and permeabilized using $0.2 \%$ Triton $\mathrm{X}-100$ for $10 \mathrm{~min}$ at room temperature. After blocking with $10 \%$ goat serum, the cells were incubated with primary antibodies overnight at $4{ }^{\circ} \mathrm{C}$. After washing with PBS, a FITC-conjugated antirabbit antibody and a TRITC-conjugated anti-mouse antibody were added, and the samples were incubated for $1 \mathrm{~h}$ at room temperature. Finally, the cells were stained with DAPI to visualize the nuclei. 


\section{Statistical analyses}

The significance of the differences was determined via one-way ANOVA or Student's t-test. Spearman's correlation coefficient was used to calculate the correlations between the two groups. Kaplan-Meier analysis was employed for survival analysis and the differences in the survival probabilities were estimated using the log-rank test. The statistical analyses were performed using GraphPad Prism or SPSS version 17.0 (SPSS, Inc.). All data was presented as mean \pm SEM. A two-sided $P<0.05$ was considered to indicate statistical significance. ${ }^{*} P<$ 0.05 and ${ }^{* *} P<0.01$ for all the analyses.

\section{Results}

\section{Depletion of Sec62 sensitizes CRC cells to} chemotherapeutic drugs

To explore novel targets in chemosensitivity, we analyzed the DEGs (differentially-expressed genes) in two
CRC cohorts consisting of chemoresistant and chemosensitive CRCs in dataset GSE28702. Eighteen genes were upregulated and 10 genes were downregulated in chemoresistant CRCs (Fig. 1a). AUC (area under curve) analysis were further performed to evaluate the involvement of candidate genes in CRC chemosensitivity using two independent datasets, GSE72968 and GSE81005 (Fig. 1b). Among these DEGs, the most significantly upregulated gene SEC62 is of particular interest since its upregulation has been found to be associated with tumorigenesis [16] and the roles of Sec62 in CRC have not yet been illustrated. We evaluated the Sec62 expression levels in human CRC tissues and show that Sec62 expression was higher in the chemoresistant CRC tissues than that in the chemosensitive ones (Fig. 1c), suggesting that Sec62 might act in the CRC chemoresistance.

Next, we depleted Sec62 with two independent shRNAs (shRNA1 and shRNA2) in CRC cell lines and

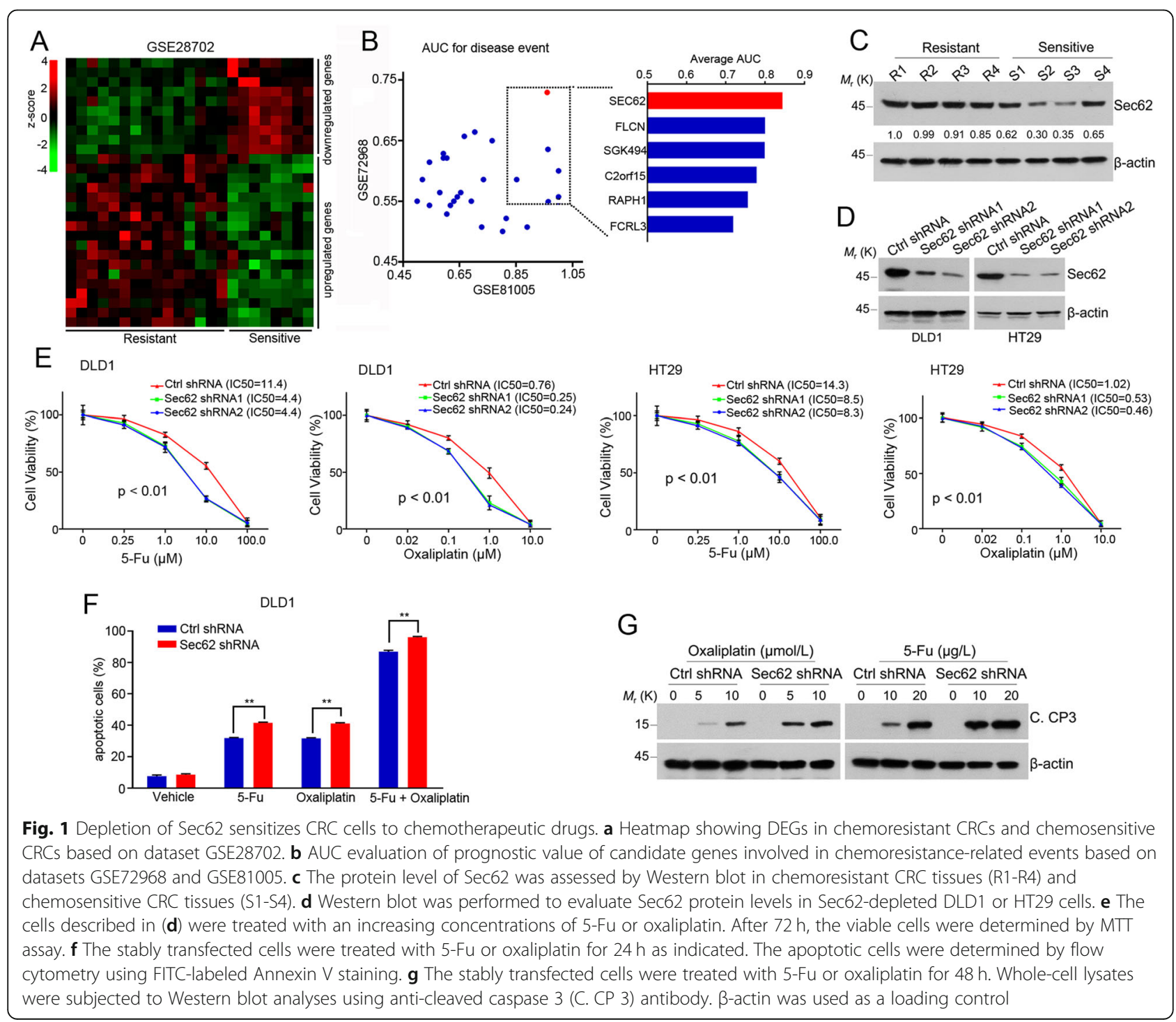


evaluated response of these cells to 5-Fu (fluorouracil) or oxaliplatin. Depletion of Sec62 sensitized the CRC cells to 5-Fu or oxaliplatin treatment ((Fig. 1d and e). Additionally, Sec62 depletion results in the increase of apoptotic cells in response to chemotherapeutic drugs (Fig. 1f). Consistently, the cleavage of Caspase 3 increased in Sec62-depleted cells under the drug treatment (Fig. 1g), confirming that depletion of Sec62 sensitizes $\mathrm{CRC}$ cells to the drug treatment. These data suggest that Sec62 suppresses the chemosensitivity of CRC cells.

\section{Sec62 maintains the stemness of CRC cells}

Since chemoresistance is a key feature of cancer stemness [22], we wanted to know if Sec62 modulates the stemness of CRC cells. Linear regression analyses using The Cancer Genome Atlas (TCGA) CRC dataset indicated that Sec62 mRNA level is positively correlated with the CSC markers/regulators including CD44, CD133, EPCAM, ITGB1 and BMI1 (Additional file:
Figure S1A), indicating that Sec62 might regulate the stemness of CRC.

To determine the effect of Sec62 on the stemness of $\mathrm{CRC}$, tumor sphere assay was employed. The number and average diameter of the spheres derived from the Sec62-depleted CRC cells were less than those derived from the control cells (Fig. 2a, b and Additional file: Figure S1B), confirming that Sec62 enhances the stemness of CSCs. Accordingly, Sec62 overexpression enhanced primary and secondary spheroid formation (Fig. 2c, d and Additional file: Figure S1C). Importantly, two CSC markers CD133 and CD44 [23, 24], were downregulated in Sec62-depleted cells (Fig. 1e). Flow cytometry analysis also showed that the percentage of cells coexpressing CD44 and CD133 was reduced when Sec62 was depleted (Fig. 2f). These data revealed that Sec62 maintains the stemness of CRC. The limited dilution assay in mice xenografts showed that loss of Sec62 caused a great reduction of CSC frequency (Fig. 2g). The shSec62 xenografts

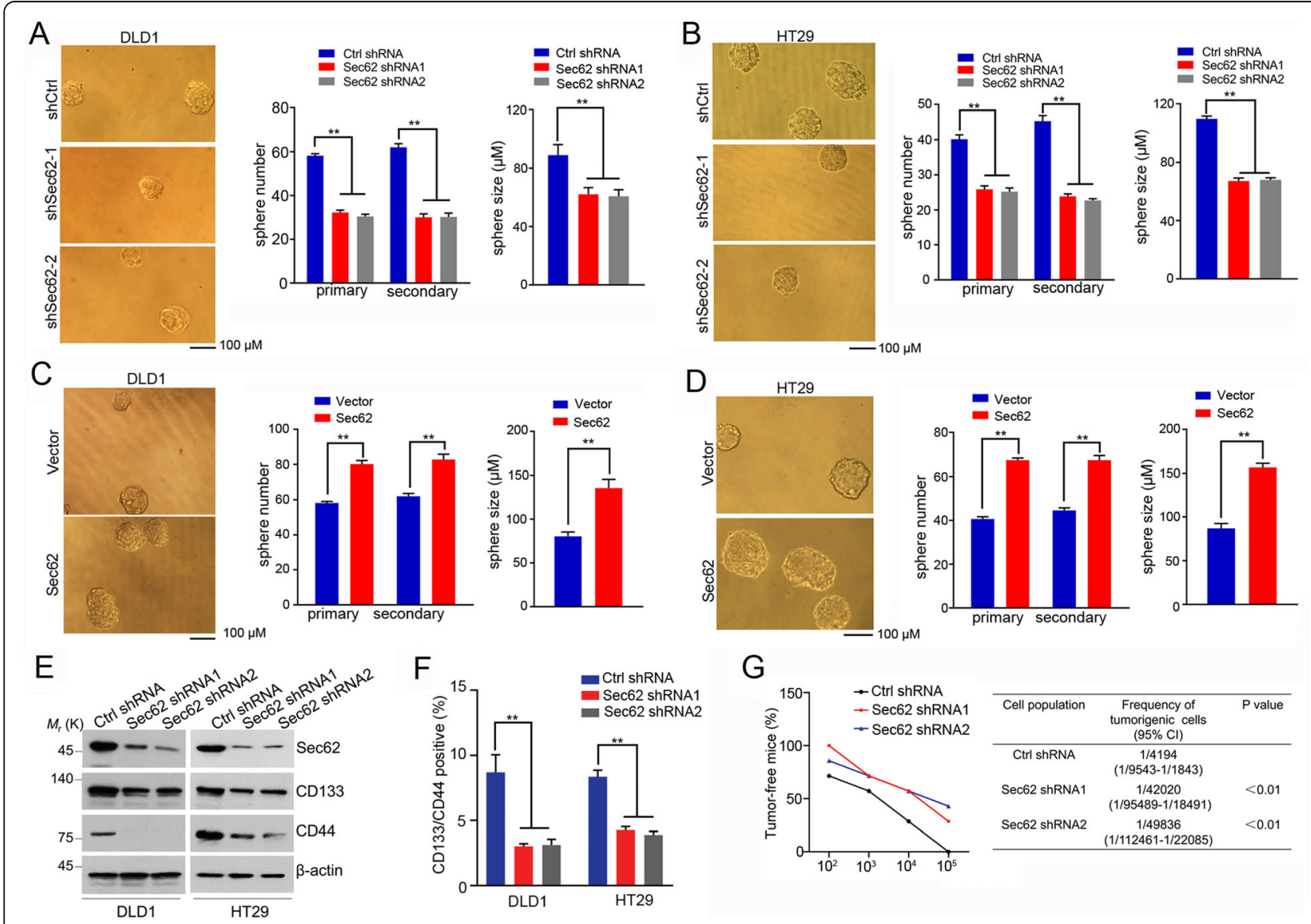

Fig. 2 Sec62 promotes the stemness of CRC cells. a-b Spheres derived from DLD1 or HT29 cells treated as indicated (left). The summary of the number and size of spheres (right) $(n=5)$. c-d Spheres derived from DLD1 or HT29 cells stably expressing Sec62 or vector cells (left). The summary of the number and size of spheres (right) $(n=5)$. e Western blot analysis was performed to determine the expression of levels of

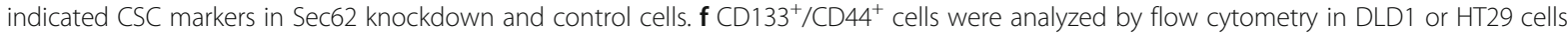
stably transcfected with Sec62 shRNA or control shRNA. g DLD1 Sec62-shRNA or DLD1 Ctrl shRNA cells were diluted and subcutaneously implanted into nude mice. Tumorigenic cell frequency was analyzed with a limiting dilution assay 
displayed lower expression levels of CD44 and CD133 than shCtrl xenografts (Additional file: Figure S1D). These results further confirmed that Sec62 promotes the stemness of CRC.

\section{Sec62 interacts with $\beta$-catenin in CRC cells and in vitro}

To uncover the mechanism by which Sec62 maintains the stemness in CRC cells, we purified the Flag-Sec62-specific immunocomplex from DLD1 cells and identified FlagSec62-interacting proteins by mass spectrometry (Fig. 3a).
Among the Flag-Sec62-interacting proteins, $\beta$-catenin is of particular interest due to its pivotal role in cancer stemness [25].

The endogenous interaction between Sec62 and $\beta$ catenin was confirmed by co-immunoprecipitation (coIP) (Fig. 3b). The co-localization of Sec62 and $\beta$-catenin was also observed in cells (Fig. 3c). The GST pull-down experiments performed with purified Sec62 and GST- $\beta$ catenin show that Sec62 specifically bound to GST- $\beta$ catenin other than GST-GSK3 $\beta$ (Fig. 3d), indicating that

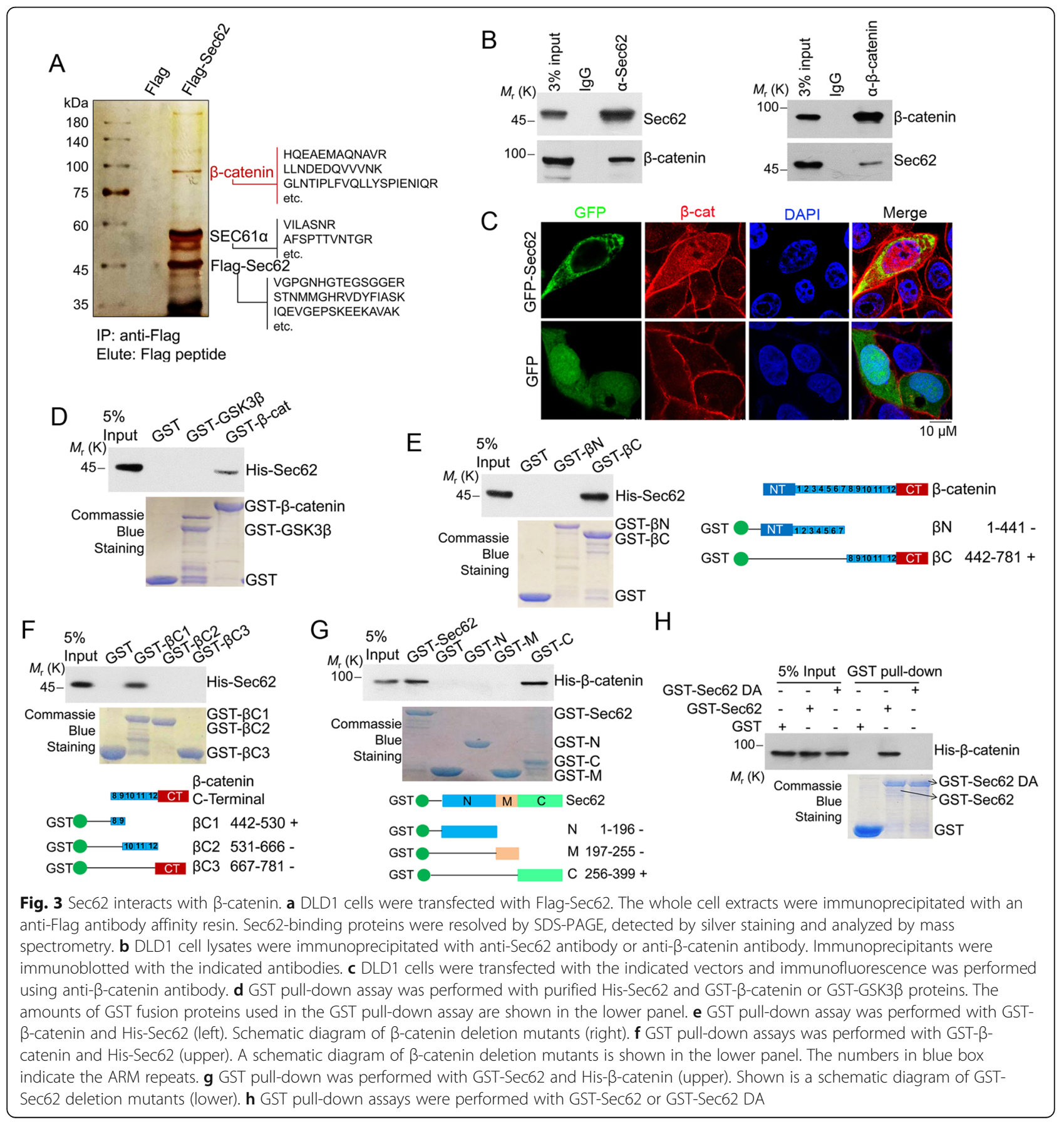


the Sec62 interacts with $\beta$-catenin in vitro. Further, the Sec62-binding region of $\beta$-catenin were narrowed down to the $8-9$ arm repeats of armadillo (ARM) domain by GST pull-down experiments (Fig. $3 \mathrm{e}$ and f). The Cterminus of Sec62 was required for the interaction with $\beta$-catenin (Fig. 3g). Most of the $\beta$-catenin's binding partners binds to $\beta$-catenin ARM repeats through the conserved DxqqxFx2-7E binding motifs ( $\mathrm{q}$ and $\mathrm{F}$ denote hydrophobic and aromatic residues, respectively) [26]. We found a similar region in Sec62 C-terminus with high sequence consensus to the $\beta$-catenin binding motif and this $\beta$-catenin binding like (BCBL) motif is highly conserved in various species (Additional file: Figure S2A). We thus constructed a GST-Sec62 deletion mutant (GST-Sec62 DA) lacking the BCBL (Additional file: Figure S2B). Indeed, the GST-Sec62 DA muant lost the capability of binding to $\beta$-catenin (Fig. $3 \mathrm{~h}$ ). Together, these results indicate that Sec62 is a novel $\beta$-catenin binding protein.

\section{Sec62 stabilizes $\beta$-catenin in APC truncated CRC cells or Wnt-stimulated CRC cells carrying wild-type APC}

Knockdown of Sec62 significantly decreased the $\beta$ catenin protein level without affecting its mRNA level in DLD1, HT29 and LOVO cells (Fig. 4a and b). This effect was reversed by the proteasome inhibitor MG132 (Fig. 4c), suggesting that Sec62 depletion promotes proteasome-mediated $\beta$-catenin degradation. Since APC is truncated in these cells, we analyzed $\beta$-catenin level after depleting Sec62 in HEK293 and RKO cells which express wild-type (WT) APC with little autocrine Wnt signaling. Depletion of Sec62 reduced $\beta$-catenin levels only when these cells were treated by Wnt3a (Fig. 4d). These findings suggest that Sec62 inhibits $\beta$-catenin degradation in APC-truncated cells or in WT APC cells when Wnt signal is present. Further, we determined if Sec62 regulates $\beta$-catenin level dependent on the BCBL motif. Flag-Sec62 and Flag-Sec62 C-terminal increased $\beta$-catenin level, while the Flag-Sec62 NM or Flag-Sec62 DA mutants lost this capability (Fig. 4e and f), indicating that Sec62 controls $\beta$-catenin level through binding to $\beta$-catenin.

The ubiquitin-proteasome system is critical for determination of protein stability, including $\beta$-catenin stability [27]. Thus, we evaluated the effect of Sec62 intervention on ubiquitination of $\beta$-catenin. Sec62 depletion enhanced poly-ubiquitination of $\beta$-catenin in DLD1 cells (Fig. 4g). Knockdown of Sec62 increased poly-ubiquitination of $\beta$ catenin in RKO cells treated with Wn3a (Fig. 4h). Accordingly, Flag-Sec62, but not the Flag-Sec62 NM or DA mutant reduced the poly-ubiquitination of $\beta$-catenin in DLD1 or RKO cells (Fig. 4i and j). These results demonstrated that Sec62 inhibits poly-ubiquitination and degradation of $\beta$-catenin.

\section{Sec62 disrupts the activity of the $\beta$-catenin destruction complex}

The activity of $\beta$-catenin destruction complex plays essential role in controlling $\beta$-catenin stability $[8,28]$. To determine if Sec62 impairs the activity of $\beta$-catenin destruction complex, the ratio of phosphorylated $\beta$-catenin/total $\beta$ catenin was evaluated as previously described [29]. The ratio of phospho- $\beta$-catenin/total $\beta$-catenin was increased upon knockdown of Sec62 in DLD1 and HT29 cells (Fig. 5a). Moreover, Sec62 depletion increased the ratio of phospho- $\beta$-catenin/total $\beta$-catenin in Wnt3a-treated HEK293 or RKO cells (Fig. 5b). In contrast, Flag-Sec62 reduced the ratio of phospho- $\beta$-catenin/total $\beta$-catenin, while the Sec62 DA mutant lost this function (Fig. 5c). Furthermore, Sec62 depletion decreased the expression of AXIN2, one of $\beta$-catenin downstream genes, and had no effect on AXIN1 level, which participates in the assembly of the $\beta$-catenin destruction complex (Additional file: Figure S3A). Taken together, our results demonstrated that Sec62 inhibits the activity of the $\beta$-catenin destruction complex to enhance $\beta$-catenin activation.

\section{Sec62 inhibits APC- $\beta$-catenin interaction}

Since Sec62 binds to the 8-9 ARM repeat domain of $\beta$ catenin which also interacts with APC, Sec62 might compete with APC for binding to $\beta$-catenin. Flag-Sec62, but neither the Flag-Sec62 DA nor Flag-Sec62 NM mutant, inhibited the interaction between $\mathrm{APC}$ and $\beta$ catenin (Fig. 5d and Additional file: Figure S3B, C), indicating that Sec62 disrupts the $\beta$-catenin-APC interaction through binding to $\beta$-catenin. Since the $15 \mathrm{aa}$ and $20 \mathrm{aa}$ repeats of APC binds to the ARM repeats $6-10$ of $\beta$ catenin [30], we thus examined the interaction between GFP-APC 15aaR1 or GFP-APC 20aaR3 and $\beta$-catenin when HA-Sec62 was overexpressed. HA-Sec62, but not the HA-Sec62 NM mutant, blocked the interaction between $\beta$-catenin and GFP-APC 15aaR1 or GFP-APC 20aaR3 (Fig. 5e), confirming that Sec62 competes with APC for the binding to $\beta$-catenin. However, the interaction between $\beta$-catenin and AXIN1 was not affected by Flag-Sec62 (Fig. 5f). Moreover, the interaction between APC and $\beta$-catenin was enhanced by knockdown of Sec62 (Fig. 5g), indicating that endogenous Sec62 attenuates the interaction between APC and $\beta$-catenin.

Given that $\beta$-catenin bridges the interaction between the truncated APC and AXIN1 in the assembly of the $\beta$ catenin destruction complex [14], we wondered if Sec62 affects the APC-AXIN1 interaction. Flag-Sec62 reduced the APC-AXIN1 interaction in DLD1 cells (Fig. 5h). Thus, Sec62 inhibits the assembly of $\beta$-catenin destruction complex by binding to $\beta$-catenin in the APCtruncated CRC cells. Then, we evaluated the effect of Sec62 on the APC-AXIN1 interaction in the cells expressing WT APC. Wnt3a treatment resulted in the 


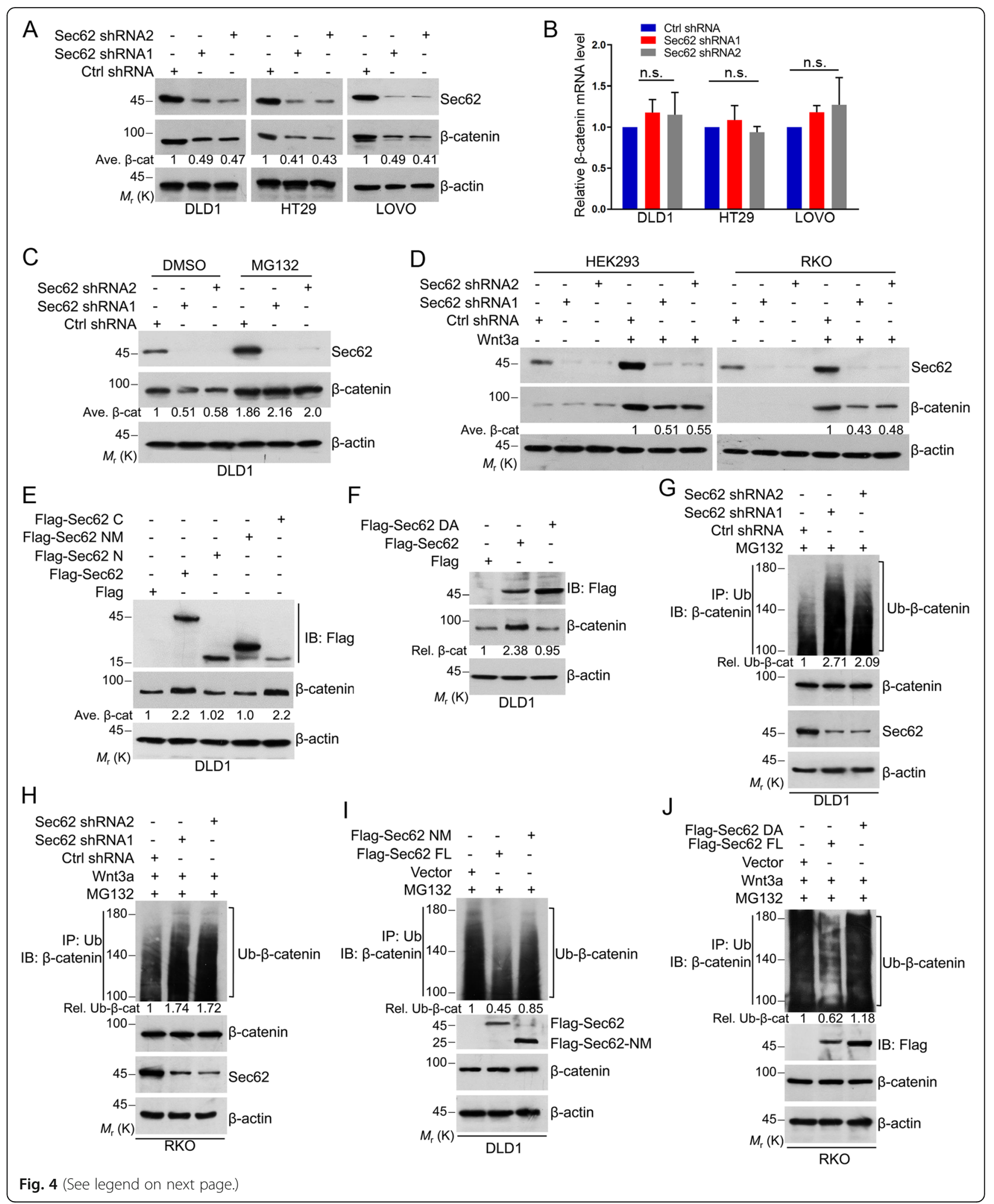


(See figure on previous page.)

Fig. 4 Sec62 stabilizes $\beta$-catenin through repressing its degradation. a Whole cell lysates extracted from the Sec62-depleted cells or control cells were subjected to Western blot using the indicated antibodies. $\mathbf{b}$ Total RNAs were extracted from Sec62-depleted and control cells and RT-qPCR were performed for evaluating the mRNA levels of $\beta$-catenin. c The Sec62-depleted and control cells were treated with MG132 and cell lystaes were subjected to Western blot performed with the indicated antibodies. $\mathbf{d}$ The Sec62-depleted and control shRNA cells were cultured in Wnt3a $(0.2 \mathrm{\mu g} / \mathrm{mL})$ contained medium for $6 \mathrm{~h}$. Cell lysates were subjected to Western blot performed with the indicated antibodies. e-f DLD1 cells were transfected with Flag-Sec62 and its deletion mutants as indicated. Cells were harvested and cell lysates were subjected to Western blot using the indicated antibodies. $\mathbf{g}$ The Sec62-depleted and control cells were treated with MG132. The ubiquitination level of $\beta$-catenin was analyzed as indicated. $\mathbf{h}$ The Sec62-depleted and control RKO cells were treated with MG132. The ubiquitination level of $\beta$-catenin was analyzed as indicated. $\mathbf{i}-\mathbf{j}$ DLD1 (i) or RKO (j) cells were transfected as indicated and treated with MG132. The ubiquitination level of $\beta$-catenin was analyzed as indicated

dissociation of APC with AXIN1 as previously reported [14] and Flag-Sec62 enhanced this effect, indicating that Sec62 reinforces the dissociation of APC-AXIN1 upon Wnt signal (Fig. 5i). Together, Sec62 protects $\beta$-catenin from degradation through inhibiting APC- $\beta$-catenin interaction.

\section{Sec62 promotes CRC progression by activating the $\beta$ - catenin signaling}

Based on the observed effect of Sec62 on $\beta$-catenin levels, we further investigated whether Sec62 regulated the nuclear translocation of $\beta$-catenin and activation of $\beta$-catenin signaling. Overexpression of Sec62 increased the nuclear accumulation of $\beta$-catenin (Fig. 6a). Moreover, Sec62 knockdown decreased $\beta$-catenin recruiment to the promoter of Wnt target genes, such as MYC and LGR5 (Fig. 6b). Accordingly, depletion of Sec62 decreased the expression of Wnt target genes including AXIN2, LGR5 and MYC (Fig. 6c), all of which play critical roles in maintaining cancer cell stemness and CRC progression [4, 31, 32]. To determine if Sec62 regulates the downstream gene of $\beta$-catenin in CRC cells expressing WT APC, we evaluated AXIN2 mRNA levels in RKO and HEK293 cells. Knockdown of Sec62 repressed the transcription of AXIN2 in the presence of Wnt3a in these cells (Fig. 6d). Moreover, Flag-Sec62, but not FlagSec62 DA mutant, upregulated AXIN2 mRNA levels and this effect was blocked by a specific $\beta$-catenin/TCF transcription inhibitor iCRT14 (Fig. 6e). Consistently, depletion of Sec62 downregulated the AXIN2 mRNA level and iCRT14 blocked this effect (Fig. 6e). Together, Sec62 promotes the $\beta$-catenin/TCF mediated transcription. We further examined if Sec62 activates $\beta$-catenin signaling dependent on BCBL motif in vivo. Overexpression of Sec62 promoted tumour growth in the mouse xenografts while Sec62 DA mutant failed to do so (Fig. $6 \mathrm{f}$ and g). Moreover, the mRNA levels of AXIN2 and LGR5 in the xenografts were upregulated by Sec62 but not by Sec62 DA mutant (Fig. 6h). Thus, Sec62 activates the $\mathrm{Wnt} / \beta$-catenin signaling by binding to $\beta$-catenin.

Next, we assessed if Sec62 controls the stemness of CRC through activating $\beta$-catenin signalling. Overexpression of Sec62 increased the number of oncosphere while Sec62 DA mutant lost this capability (Fig. 6i and j). Further, overexpression of Sec62 failed to potentiate the stemness when $\beta$-catenin was depleted, demonstrating that Sec62 maintains the stemness of CRC dependent on $\beta$-catenin. Clony formation was decreased by 5 -Fu or oxaliplatin and this effect was reversed by overexpression of Sec62 but not the Sec62 DA mutant, indicating that Sec62 attenuates the chemosensitivity of CRC cells through activating $\beta$-catenin (Fig. 6k). Collectively, we demonstrated that Sec62 maintains the stemness by activating the Wnt signalling pathway in CRC.

\section{Upregulation of Sec62 correlates with poor prognosis of CRC patients}

We next determined the relationship between the Sec62 expression and prognosis of the CRC patients. Sec62 expression was evaluated by IHC in 102 cases of CRC samples. Sec62 was upregulated in the cancer tissues compared with non-cancerous tissues and significantly increased at clinical stage IV (Fig. 7a and b). Importantly, the high Sec62 expression was correlated with shorter overall survival and disease-free survival in the patients (Fig. 7c and d). The GSE17538 data also showed that high Sec62 expression predicts shorter survival in 271 cases of CRC patients (Fig. 7e). These findings indicate that Sec62 is upregulated in CRC and predicts poor prognosis of CRC patients. The expression of Sec62 and $\beta$-catenin on 16 paired cancerous and matched noncancerous sections of human CRC tissues was evaluated by immunoblotting. Sec62 expression was significantly correlated with $\beta$-catenin in CRC tissues (Fig. 7f). Moreover, Sec62 expression was positively correlated with the expression of $\beta$-catenin downstream genes, including CD44 and MYC, in CRC tissues (Additional file: Figure S4A), indicating that Sec62 activates $\beta$-catenin in CRC tissues.

We further explored if Sec62 affects the chemosensitivity of CRC cells in vivo. The nude mice bearing tumor xenograft were injected with control lentivirus (shCtrl) or Sec62 shRNA (shSec62)-lentivirus. Meanwhile, 5-Fu or oxaliplatin was injected. The results showed that Sec62 knockdown effectively attenuated tumor growth as 5 -Fu or oxaliplatin did (Fig. $7 \mathrm{~g}$ and h). Tumors treated with Sec62-shRNA lentivirus were more sensitive to 5 -Fu or oxaliplatin when compared with those treated 


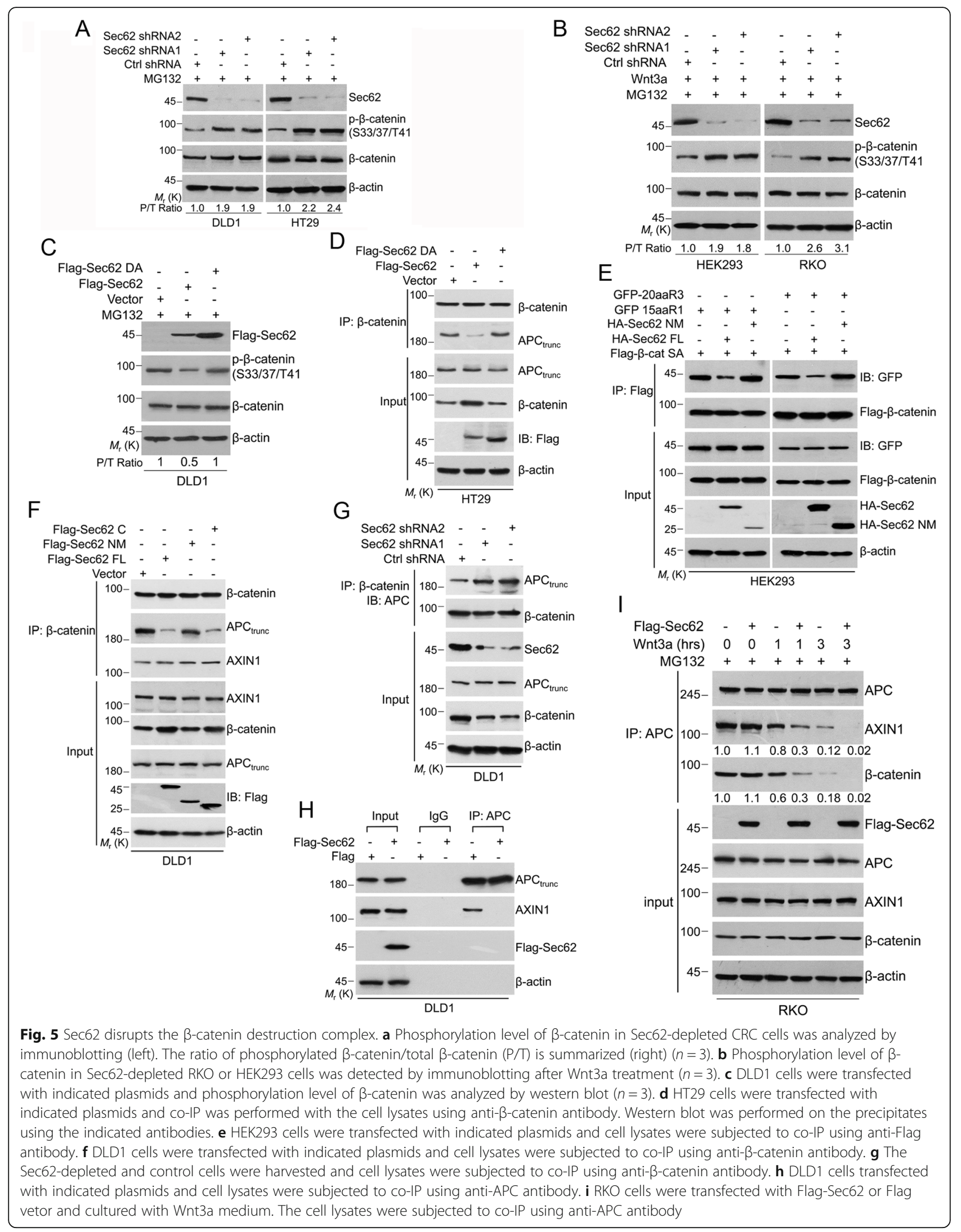




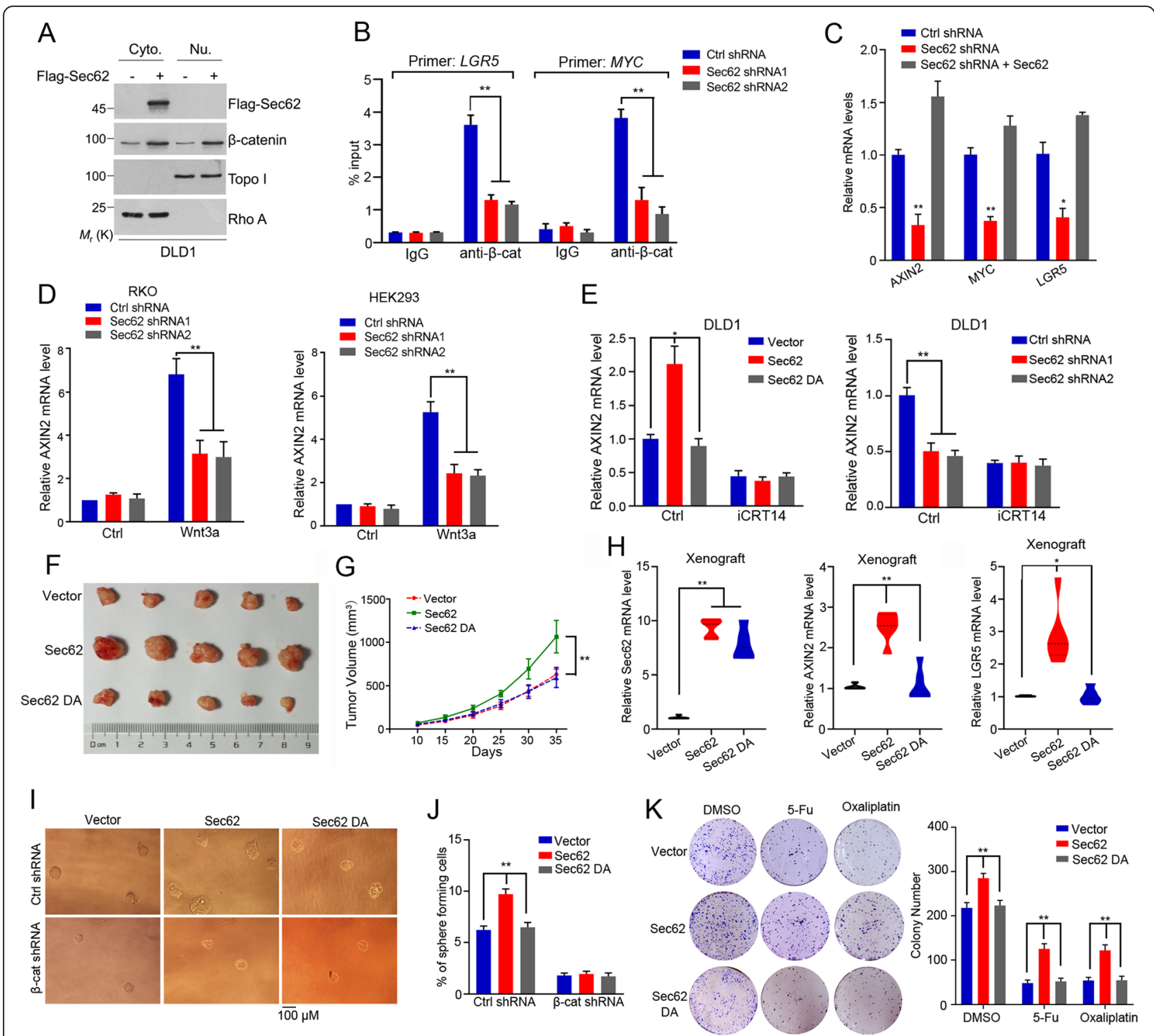

Fig. 6 Sec62 promotes CRC progression by activating $\beta$-catenin signaling. a DLD1 cells were transfected with indicated vectors. Cell fraction was performed and the nuclear $\beta$-catenin was evaluated by Western blot. b DLD1 cells were treated as indicated. The promoter occupancy of LGR5 or MYC by $\beta$-catenin was analyzed by ChIP assay. c The Sec62 depleted and control cells were transfected with Sec62 plasmid. RT-qPCR was performed to analyze the mRNA levels of the indicated genes. $\mathbf{d}$ The Sec62-depleted and control cells were treated with Wnt3a. Total RNAs were extracted and RT-qPCR was performed as indicated. e The Sec62-depleted and control cells were treated with iCRT14 (50 $\mu \mathrm{M}$ for 24 h). RT-qPCR was performed to analyze the mRNA levels of the indicated genes. $\mathbf{f}$ Tumor formation in nude mice injected with Sec62-overexpressed, Sec62 DA-overexpressed DLD-1 or control cells. $\mathbf{g}$ The tumor growth curves of each group of mice were summarized $(n=5)$. $\mathbf{h}$ Total RNAs were extracted from the xenografts obtained in (F). RT-qPCR was performed for evaluating the indicated genes $(n=5)$. i-j DLD1 cells were infected with indicated lentivirus and sphere formation assays were performed in sphere-formation medium (i). The number of spheres derived from indicated cells were summarized (j) $(n=6)$. $\mathbf{k}$ Colony number quantification of the DLD1 cells after treatment with 5-Fu or oxaliplatin ( $n=6)$

with control-shRNA lentivirus, indicating that Sec62 suppresses the chemosensitivity of CRC cells. IHC confirmed that the expression of Sec62 was inhibited by lentiviral-shSec62 in xenografts (Fig. 7i). Accordingly, Sec62 depletion caused more apoptotic cells upon 5-Fu or oxaliplatin treatment (Fig. 7i). The shSec62 xenografts displayed lower expression levels of CD44 and c-Myc than shCtrl xenografts, indicating that Sec62 promoted the activation of $\beta$-catenin (Additional file: Figure S4B). These data demonstrated that depletion of Sec62 sensitized CRC cells to chemotherapeutics in vivo.

\section{Sec62 expression is regulated by the METTL3-induced $\mathrm{m}^{6} \mathrm{~A}$ modification}

Finally, we explored how Sec62 is overexpressed in cancers. Since both the mRNA and protein levels of Sec62 


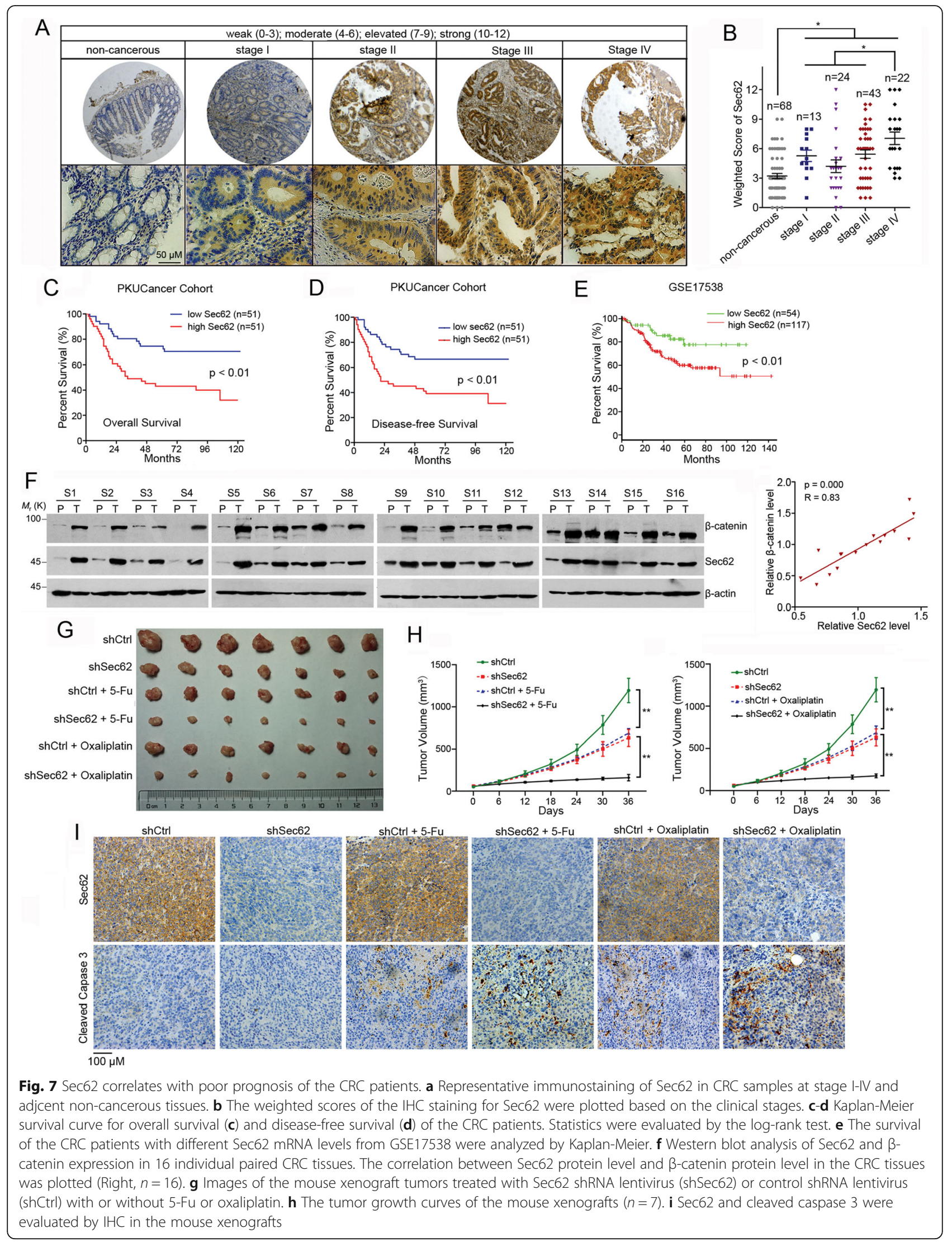


are upregulated in CRC tissues, Sec62 expression might be regulated at mRNA level. Numerous $\mathrm{m}^{6} \mathrm{~A}$ sites were found in Sec62 mRNA by RMBase prediction, suggesting that Sec62 mRNA might be controlled by $\mathrm{m}^{6} \mathrm{~A}$ modification. We show that $\mathrm{m}^{6} \mathrm{~A}$ was significantly more enriched in Sec62 mRNA in DLD1 or SW480 cells than that in normal colorectal cell NCM460 (Fig. 8a). We found that METTL3 depletion reduced Sec62 mRNA and protein levels (Fig. 8b and c). Importantly, depletion of METTL3 decreased $\mathrm{m}^{6} \mathrm{~A}$ modification of Sec62 mRNA (Fig. 8d). Accordingly, Flag-METTL3 increased Sec62 protein level (Fig. 8e). These data revealed that Sec62 is upregulated by METTL3-induced $\mathrm{m}^{6} \mathrm{~A}$ modification of Sec62 mRNA.

Since $\mathrm{m}^{6} \mathrm{~A}$ modification controls mRNAs stability [33], we evaluated the Sec62 mRNA stability upon METTL3 knockdown. The Sec62 mRNA stability was decreased by METTL3 depletion (Fig. 8f), while it was increased by Flag-METTL3, indicating that METTL3 enhances Sec62 mRNA stability by controlling its $\mathrm{m}^{6} \mathrm{~A}$ modification. It's reported that IGF2BP1 (Insulin-like growth factor 2 mRNA-binding protein 1 ), a "reader" of $\mathrm{m}^{6} \mathrm{~A}$, plays a specific role in reading $\mathrm{m}^{6} \mathrm{~A}$ and controlling the stability of $\mathrm{m}^{6} \mathrm{~A}$-modified mRNA [34]. We showed that IGF2BP1 interacted with Sec62 mRNA in CRC cells (Fig. 8g) and silencing IGF2BP1 decreased Sec62 expression levels (Fig. 8h). The half-life of Sec62 mRNA was reduced upon IGF2BP1 depletion (Fig. 8i). Finally, the interaction between IGF2BP1 and Sec62 mRNA was impaired after METTL3 depletion (Fig. 8j), indicating that IGF2BP1 binds to the $\mathrm{m}^{6} \mathrm{~A}$-modified Sec62 mRNA to maintain the Sec62 mRNA stability. Additionally, METTL3 or IGF2BP1 expression was positively correlated with Sec62 expression in CRC tissues (Fig. 8k). Together, we demonstrated that Sec62 is upregulated by $\mathrm{m}^{6} \mathrm{~A}$-mediated stabilization of Sec62 mRNA in CRC.

\section{Discussion}

Chemosensitivity of CRC cells plays crucial roles in cancer treatment, which is tightly associated with cancer stem cells [22]. However, the mechanisms involved in the regulation of the colorectal cancer stem cells need to be clarified. In the present study, we set out to screen the chemosensitivity-related targets using GEO datasets [35-37], aiming to identify novel molecules regulating stemness and chemosensitivity in CRC. SEC62 is one of the most significantly upregulated gene in chemoresistant CRCs in the screening. We further show that depletion of Sec62 sensitizes CRC cells to drug treatment and attenuates cancer stemness. Thus, inhibition of Sec62 function might be a potential therapeutic strategy to ameliorate chemoresistance in CRC.

Sec62 was initially found as a translocation-related protein in the membrane of endoplasmic reticulum [38,
39]. Recent studies have reported that Sec62 is correlated with metastasis in breast cancer and promotes recurrence of hepatocellular carcinoma, suggesting that Sec62 is associated with cancer progression [40, 41]. However, the mechanism by which Sec62 acts in the tumorigenesis remains unknown. In this study, we identified Sec62 as an important regulator of CRC stemness. Sec62 is upregulated in CRC and its overexpression is associated with poor prognosis of the patients. We further demonstrated that Sec62 promotes cancer stemness and CRC progression through enhancing Wnt/ $\beta$-catenin signaling.

Activation of Wnt signaling leads to the stabilization of $\beta$-catenin to upregulate the transcription of its dowmstream genes [8]. $\beta$-catenin is abnormally activated in most of CRC patients, making it become a crucial therapeutic target $[25$, 42]. The accumulation of nuclear $\beta$-catenin enhances both chemoresistance and radioresistance in advanced rectal cancer [43]. Inhibitors of $\beta$-catenin signaling have been used to attenuate chemoresistance in CRC. For instance, the $\beta$-catenin inhibitor IC-2 increased the cytotoxicity of 5$\mathrm{Fu}$ and downregulated the expression of CSC markers in CRC cells [44]. Zerumbone could suppress the stemness of CRC by inhibiting the $\beta$-catenin signaling [45]. Therefore, identification of molecules blocking the $\mathrm{Wnt} / \beta$-catenin signaling would contribute to improve the chemotherapeutics in CRC. Here, we demonstrate that Sec62 enhances $\beta$ catenin stability and potentiates $\beta$-catenin signaling in CRC cells. Targeting Sec62 could improve the chemotherapeutic effect in Sec62-upregulated CRC patients by inhibiting $\beta$ catenin signaling.

Since the $\beta$-catenin destruction is the critical event in the $\mathrm{Wnt} / \beta$-catenin signaling, the regulation of $\beta$ catenin stabilization will provide molecular evidence for understanding the activation of $\mathrm{Wnt} / \beta$-catenin signaling. As a critical negative regulator of $\mathrm{Wnt} / \beta$-catenin signaling, APC is essential for the assembly of the $\beta$-catenin destruction complex to destroy $\beta$ catenin. Since the SAMP repeats in APC are truncated leading to the loss of APC-AXIN1 interaction in $75 \%$ of CRC [13], the interaction between APC and $\beta$-catenin is critical for the assembly of the $\beta$ catenin destruction complex. Disruption of APC- $\beta$ catenin interaction often leads to hyperactivation of $\beta$-catenin in CRCs. However, the molelcular mechanism by which the APC- $\beta$-catenin is regulated remains unclear. APC binds to the ARM repeats $6-10$ of $\beta$ catenin through its $15 \mathrm{aa}$ and 20aa repeats to facilitate the $\beta$-catenin degredation [14]. Here, we found that Sec62 binds to the ARM repeats $8-9$ of $\beta$-catenin through the $\mathrm{BCBL}$ motif and inhibited the interaction between $\beta$-catenin and APC. Moreover, Sec62 disrupts the assembly of the $\beta$-catenin destruction complex and promotes $\beta$-catenin activation. Significantly, 


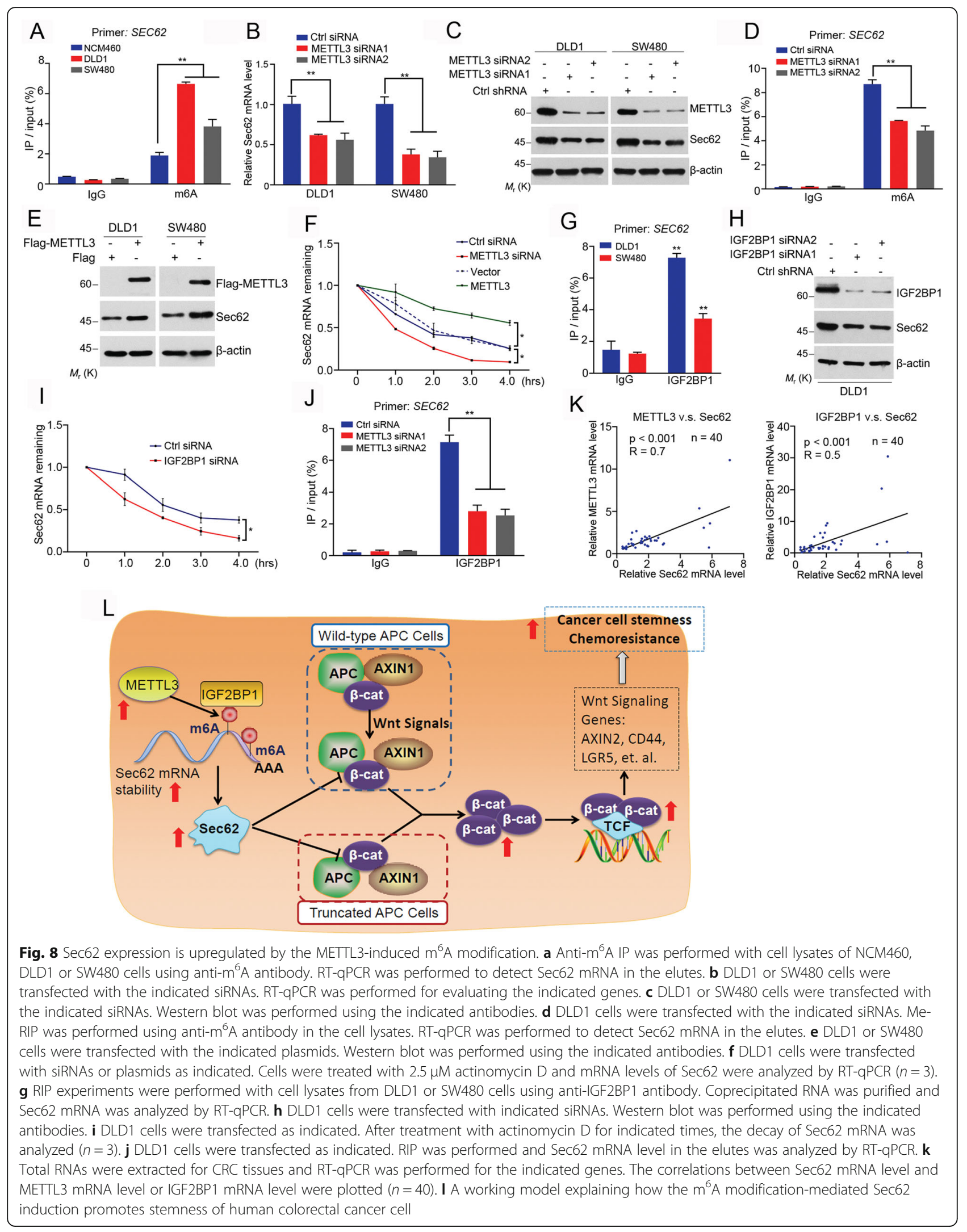


Sec62 maintains the stemness of CRC by enhancing the $\beta$-catenin signaling depending on the BCBL motif. Thus, we demonstrated that Sec62 activates $\beta$-catenin in the APC-truncated CRC. We further found that Sec62 activates $\beta$-catenin in the CRC cells expressing WT APC when Wnt signal is present. The Sec62mediated $\beta$-catenin activation is verified by the coupregulation of Sec62 and $\beta$-catenin in the CRC tissues. We thus provide Sec62 as a key activator of $\beta$ catenin in CRC.

Aberrant overexpression of Sec62 has been found in various tumors, but the underlying mechanism was unknown. Recently, accumulated studies show that $\mathrm{m}^{6} \mathrm{~A}$ modification is one of important epigenetic regulatory mechanisms and is involved in pre-mRNA splicing, RNA stability and translation efficiency [46]. Dysregulated $\mathrm{m}^{6} \mathrm{~A}$ modification of specific mRNAs is associated with cancer development and progression. As a $\mathrm{m}^{6} \mathrm{~A}$ 'wiriter', METTL3 participates in the persisting stem-like phenotype and preventing the radiation-induced cytotoxicity through modulating mRNA stability such as SOX2 and CBX8 in the $\mathrm{m}^{6} \mathrm{~A}$ dependent manner $[20,47]$. Here, we show that $\mathrm{m}^{6} \mathrm{~A}$ modification induced by METTL3 increased the stability of Sec62 mRNA, leading to upregulation of Sec62 in CRC. Thus, our findings provide SEC62 as a new target gene regulated by METTL3 in the regulation of CRC cell stemness. The $\mathrm{m}^{6} \mathrm{~A}$ "readers", IGF2BP1, recognizes the consensus $G G\left(\mathrm{~m}^{6} \mathrm{~A}\right) \mathrm{C}$ sequence and enhances the stability of targeted mRNAs in an $\mathrm{m}^{6} \mathrm{~A}$-dependent way [34]. In the present study, we found that IGF2BP1 binds to Sec62 mRNA and upregulates Sec62 expression in an $\mathrm{m}^{6} \mathrm{~A}$-dependent manner, which is consistent with previous findings.

\section{Conclusions}

In summary, we show for the first time that Sec62 is commonly upregulated in CRC and its overexpression is associated with poor survival for patients with CRC. METTL3-mediated $\mathrm{m}^{6} \mathrm{~A}$ modification of Sec62 mRNA upregulated Sec62 expression in CRC. Subsequently, Sec62 potentiates Wnt signaling through repressing $\beta$ catenin binding to APC complex, thus facilitates CRC cell stemness and chemoresistance (Fig. 7l). Therefore, Sec62 might be a potential target for CRC treatment.

\section{Abbreviations}

CRC: Colorectal cancer; CSC: Cancer stem cell; ER: Endoplasmic reticulum; DEGs: Differentially-expressed genes; AUC: Area under curve; BCBL: $\beta$-catenin binding like; ARM: Armadillo; AXIN1: Axis inhibition protein 1;

APC: Adenomatous polyposis coli; METTL3: Methyltransferase-like protein 3; LGR5: Leucine-rich repeat-containing G-protein coupled receptor 5;

IGF2BP1: Insulin-like growth factor 2 mRNA-binding protein 1; WT: Wild-type; RIP: RNA immunoprecipitation; IHC: Immunohistochemistry; RT-qPCR: Realtime quantitative PCR

\section{Supplementary Information}

The online version contains supplementary material available at https://doi. org/10.1186/s13046-021-01934-6.

Additional file 1: Figure S1. Sec62 is involved in maintaining the stemness of CRC cells. a, Scatter plots of mRNA level of Sec62 versus mRNA levels of CD44, CD133, EPCAM, ITGB1, and BMI1 in colon adenocarcinoma from TCGA dataset were plotted. b, The control cells or Sec62 depleted cells were seeded in unattached 96-well plates and cultured for 7 day. The percentage of wells with spheres was evaluated and calculated with limiting dilution analysis (LDA) to determine the sphereinitiating cell frequency. Frequency and probability estimates were computed using the ELDA software. ${ }^{* *}, P<0.001$. c, Sec62-overexpressed clones and the vector transcfected control cells were generated from DLD1 or HT29 cells. The protein levels of Sec62 in the stable clones were examined by Western blot. d, Western blot was performed as indicated using mice xenografts in Fig. 2 g. Figure S2. Sec62 interacts with $\beta$ catenin. a, The amino acid sequences of Sec62 BCBL motif from different species were aligned. The critical conserved site of Sec62 is indicated by the red box. b, DA mutant lacking BCBL motif. Figure S3. Sec62 inhibits the APC- $\beta$-catenin interaction. $\mathbf{a}$, DLD1 or HT29 cells were transfected as indicated. Then, cells were harvested and total proteins were subjected to Western blot using the indicated antibodies. b, RKO cells were transfected with the indicated plasmids. Co-immunoprecipitation assay was performed with anti-Flag antibody and the indicated proteins were evaluated by Western blot. c, DLD1 cells were transfected with the indicated plasmids. Co-immunoprecipitation assay was performed with anti- $\beta$ catenin antibody and the indicated proteins were evaluated by Western blot. Figure S4. Sec62 maintains the stemness of CRC by activating $\beta$ catenin signaling. a, Western blot analysis of Sec62, $\beta$-catenin, CD44 and c-Myc expression in 16 individual paired CRC tissues. b. Western blot was performed as indicated using mice xenografts in Fig. $7 \mathrm{~g}$. The relative CD44 or c-Myc protein levels were summarized (right). Supplemental Table S1. Reagents and antibodies. Supplemental Table S2. Correlation of Sec62 expression with clinicopathologic status in 102 cases of patients with colorectal cancer. Supplemental Table S3. shRNA sequence. Supplemental Table S4. Primer used for RT-qPCR.

\section{Acknowledgements}

We thank Dr. Qihua He (Peking University Health Sicence Center) for assistance with confocal microscopy, Dr. Hounan Wu (Peking University Health Sicence Center) for flow cytometry assistance and Dr. Xuyang Zhao (Peking University Health Sicence Center) for assisting in the mass spectrometric analysis. We thank Prof. Wengong Wang for providing us the METTL3 plasmid.

\section{Authors' contributions}

XF Liu, XJ Du, and BC Xing designed the project. XF Liu, KQ Su, Y Jiang, XY Sun, $C Y$ Hu and CF Zhang performed the experiments and collected data. XF Liu, KQ Su, CF Zhang, M Lu and XJ Du analyzed the data. LJ Wang and CF Zhang collected tissue samples. XF Liu, XJ Du and BC Xing supervised the project. XF Liu, XJ Du and BC Xing prepared the manuscript with input from all authors. The author(s) read and approved the final manuscript.

\section{Funding}

This work was supported by the grants from the National Natural Science Foundation of China [Grant No. 81802305], the Beijing Natural Science Foundation [Grant No.7192035], the National Natural Science Foundation of China [Grant No. 81874143] and the Science Foundation of Peking University Cancer Hospital 2020-1.

\section{Availability of data and materials}

All data generated or analyzed during this study are included in this article and its supplementary files.

\section{Declarations}

Ethics approval and consent to participate

This study was reviewed and approved by the Ethics Committee of Peking University Cancer Hospital \& Institute, and written informed consent was 
obtained from all patients. All animal experiments were reviewed and approved by the Ethics Review Committee of Peking University Health science Center.

\section{Consent for publication}

All the authors agree to the content of the paper and their being listed as a co-author of the paper.

\section{Competing interests}

The authors declare no competing interests.

\section{Author details \\ 'Hepatopancreatobiliary Surgery Department I, Key laboratory of Carcinogenesis and Translational Research (Ministry of Education/Beijing), Peking University Cancer Hospital \& Institute, Beijing 100142, China. ${ }^{2}$ Department of Cell Biology, School of Basic Medical Sciences, Peking University Health Science Center, Beijing 100191, China. ${ }^{3}$ Department of Medical Genetics, School of Basic Medical Sciences, Peking University Health Science Center, Beijing 100191, China. ${ }^{4}$ Department of Pathology, School of Basic Medical Sciences, Peking University Health Science Center, Beijing 100191, China.}

\section{Received: 30 December 2020 Accepted: 30 March 2021 Published online: 15 April 2021}

\section{References}

1. Dekker E, Tanis PJ, Vleugels JLA, Kasi PM, Wallace MB. Colorectal cancer. Lancet. 2019;394(10207):1467-80. https://doi.org/10.1016/S0140-6736(1 9)32319-0.

2. Xu D, Liu XF, Yan XL, Wang K, Xing BC. Survival prediction in patients with resectable colorectal liver metastases: clinical risk scores and tumor response to chemotherapy. Oncol Lett. 2017;14(6):8051-9. https://doi.org/1 0.3892/ol.2017.7191.

3. Siegel RL, Miller KD, Goding Sauer A, Fedewa SA, Butterly LF, Anderson JC, Cercek A, Smith RA, Jemal A. Colorectal cancer statistics, 2020. CA Cancer J Clin. 2020;

4. Ramos EK, Hoffmann AD, Gerson SL, Liu H. New opportunities and challenges to defeat cancer stem cells. Trends Cancer. 2017;3(11):780-96. https://doi.org/10.1016/j.trecan.2017.08.007.

5. Fulda S. Regulation of apoptosis pathways in cancer stem cells. Cancer Lett. 2013;338(1):168-73. https://doi.org/10.1016/j.canlet.2012.03.014

6. Wang J, Xing Y, Wang Y, He Y, Wang L, Peng S, Yang L, Xie J, Li X, Qiu W, Yi Z, Liu M. A novel BMI-1 inhibitor QW24 for the treatment of stem-like colorectal cancer. J Exp Clin Cancer Res. 2019;38(1):422. https://doi.org/10.11 86/s13046-019-1392-8.

7. Nusse R, Clevers H. Wnt/beta-catenin signaling, disease, and emerging therapeutic modalities. Cell. 2017;169(6):985-99. https://doi.org/10.1016/j. cell.2017.05.016.

8. Shen C, Wang D, Liu X, Gu B, Du Y, Wei FZ, Cao LL, Song B, Lu X, Yang O, et al. SET7/9 regulates cancer cell proliferation by influencing beta-catenin stability. FASEB J. 2015;29(10):4313-23. https://doi.org/10.1096/fj.15-273540.

9. Deitrick J, Pruitt WM. Wnt/beta catenin-mediated signaling commonly altered in colorectal cancer. Prog Mol Biol Transl Sci. 2016;144:49-68. https:// doi.org/10.1016/bs.pmbts.2016.09.010.

10. Yang D, Li Q, Shang R, Yao L, Wu L, Zhang M, Zhang L, Xu M, Lu Z, Zhou J, Huang $L$, Huang $X$, Cheng D, Yang $Y, Y u ~ H$. WNT4 secreted by tumor tissues promotes tumor progression in colorectal cancer by activation of the WNT/ beta-catenin signalling pathway. J Exp Clin Cancer Res. 2020;39(1):251. https://doi.org/10.1186/s13046-020-01774-w

11. Luo Q, Wu X, Chang W, Zhao P, Nan Y, Zhu X, Katz JP, Su D, Liu Z. ARID1A prevents squamous cell carcinoma initiation and chemoresistance by antagonizing pRb/E2F1/c-Myc-mediated cancer stemness. Cell Death Differ. 2020:27(6):1981-97. https://doi.org/10.1038/s41418-019-0475-6.

12. Mendoza-Topaz C, Mieszczanek J, Bienz M. The adenomatous polyposis coli tumour suppressor is essential for Axin complex assembly and function and opposes Axin's interaction with Dishevelled. Open Biol. 2011;1(3):110013. https://doi.org/10.1098/rsob.110013.

13. Cowie S, Drmanac S, Swanson D, Delgrosso K, Huang S, du Sart D, Drmanac $R$, Surrey S, Fortina P. Identification of APC gene mutations in colorectal cancer using universal microarray-based combinatorial sequencing-by- hybridization. Hum Mutat. 2004;24(3):261-71. https://doi.org/10.1002/ humu.20078.

14. Ji L, Lu B, Wang Z, Yang Z, Reece-Hoyes J, Russ C, Xu W, Cong F. Identification of ICAT as an APC inhibitor, revealing Wnt-dependent inhibition of APC-Axin interaction. Mol Cell. 2018;72(1):37-47 e34. https:// doi.org/10.1016/j.molcel.2018.07.040.

15. Conti BJ, Devaraneni PK, Yang Z, David LL, Skach WR. Cotranslational stabilization of Sec62/63 within the ER Sec61 translocon is controlled by distinct substrate-driven translocation events. Mol Cell. 2015;58(2):269-83. https://doi.org/10.1016/j.molcel.2015.02.018.

16. Linxweiler M, Schick B, Zimmermann R. Let's talk about Secs: Sec61, Sec62 and Sec63 in signal transduction, oncology and personalized medicine. Signal Transduct Target Ther. 2017;2(1):17002. https://doi.org/10.1038/sigtra ns.2017.2.

17. Linxweiler M, Bochen F, Schick B, Wemmert S, Al Kadah B, Greiner M, Hasenfus A, Bohle RM, Juhasz-Boss I, Solomayer EF, Takacs ZF. Identification of SEC62 as a potential marker for $3 q$ amplification and cellular migration in dysplastic cervical lesions. BMC Cancer. 2016;16(1):676. https://doi.org/10.11 86/s12885-016-2739-6.

18. Hagerstrand D, Tong A, Schumacher SE, llic N, Shen RR, Cheung HW, Vazquez F, Shrestha Y, Kim SY, Giacomelli AO, Rosenbluh J, Schinzel AC, Spardy NA, Barbie DA, Mermel CH, Weir BA, Garraway LA, Tamayo P, Mesirov JP, Beroukhim R, Hahn WC. Systematic interrogation of 3q26 identifies TLOC1 and SKIL as cancer drivers. Cancer Discov. 2013:3(9):1044 57. https://doi.org/10.1158/2159-8290.CD-12-0592.

19. Liu X, Cai S, Zhang C, Liu Z, Luo J, Xing B, Du X. Deacetylation of NAT10 by Sirt1 promotes the transition from rRNA biogenesis to autophagy upon energy stress. Nucleic Acids Res. 2018;46(18):9601-16. https://doi.org/10.1 093/nar/gky777.

20. Zhang Y, Kang M, Zhang B, Meng F, Song J, Kaneko H, Shimamoto F, Tang B. $m$ (6) A modification-mediated CBX8 induction regulates stemness and chemosensitivity of colon cancer via upregulation of LGR5. Mol Cancer. 2019;18(1):185. https://doi.org/10.1186/s12943-019-1116-x.

21. Dominissini D, Moshitch-Moshkovitz S, Salmon-Divon M, Amariglio N, Rechavi G. Transcriptome-wide mapping of $N(6)$-methyladenosine by $m$ (6) A-seq based on immunocapturing and massively parallel sequencing. Nat Protoc. 2013;8(1):176-89. https://doi.org/10.1038/nprot.2012.148.

22. Yang L, Shi P, Zhao G, Xu J, Peng W, Zhang J, Zhang G, Wang X, Dong Z, Chen $\mathrm{F}$, Cui H. Targeting cancer stem cell pathways for cancer therapy. Signal Transduct Target Ther. 2020;5(1):8. https://doi.org/10.1038/s41392-020-0110-5.

23. Jin L, Vu T, Yuan G, Datta PK. STRAP promotes Stemness of human colorectal cancer via epigenetic regulation of the NOTCH pathway. Cancer Res. 2017:77(20):5464-78. https://doi.org/10.1158/0008-5472.CAN-17-0286.

24. Kim BR, Na YJ, Kim JL, Jeong YA, Park SH, Jo MJ, Jeong S, Kang S, Oh SC, Lee DH. RUNX3 suppresses metastasis and stemness by inhibiting hedgehog signaling in colorectal cancer. Cell Death Differ. 2020;27(2):67694. https://doi.org/10.1038/s41418-019-0379-5.

25. de Sousa EMF, Vermeulen L. Wnt signaling in cancer stem cell biology. Cancers (Basel). 2016:8

26. Xu W, Kimelman D. Mechanistic insights from structural studies of betacatenin and its binding partners. J Cell Sci. 2007;120(19):3337-44. https://doi. org/10.1242/jcs.013771.

27. Chen J, Rajasekaran M, Xia H, Zhang X, Kong SN, Sekar K, Seshachalam VP, Deivasigamani A, Goh BK, Ooi LL, et al. The microtubule-associated protein PRC1 promotes early recurrence of hepatocellular carcinoma in association with the Wnt/beta-catenin signalling pathway. Gut. 2016;65(9):1522-34. https://doi.org/10.1136/gutjnl-2015-310625.

28. Schaefer KN, Peifer M. Wnt/Beta-catenin signaling regulation and a role for biomolecular condensates. Dev Cell. 2019;48(4):429-44. https://doi.org/10.1 016/j.devcel.2019.01.025

29. Hernandez AR, Klein AM, Kirschner MW. Kinetic responses of beta-catenin specify the sites of Wnt control. Science. 2012:338(6112):1337-40. https:// doi.org/10.1126/science.1228734

30. Ha NC, Tonozuka T, Stamos UL, Choi HJ, Weis WI. Mechanism of phosphorylation-dependent binding of APC to beta-catenin and its role in beta-catenin degradation. Mol Cell. 2004;15(4):511-21. https://doi.org/10.101 6/j.molcel.2004.08.010

31. Yeung J, Esposito MT, Gandillet A, Zeisig BB, Griessinger E, Bonnet D, So CW beta-catenin mediates the establishment and drug resistance of MLL leukemic stem cells. Cancer Cell. 2010;18(6):606-18. https://doi.org/10.1016/j. ccr.2010.10.032 
32. Zhang J, Ren P, Xu D, Liu X, Liu Z, Zhang C, Li Y, Wang L, Du X, Xing B. Human UTP14a promotes colorectal cancer progression by forming a positive regulation loop with c-Myc. Cancer Lett. 2019;440-441:106-15. https://doi.org/10.1016/j.canlet.2018.10.010.

33. Roundtree IA, Evans ME, Pan T, He C. Dynamic RNA modifications in gene expression regulation. Cell. 2017;169(7):1187-200. https://doi.org/10.1016/j. cell.2017.05.045.

34. Huang $H$, Weng $H$, Sun $W$, Qin $X$, Shi H, Wu H, Zhao BS, Mesquita A, Liu C, Yuan CL, Hu YC, Hüttelmaier S, Skibbe JR, Su R, Deng X, Dong L, Sun M, Li C, Nachtergaele S, Wang Y, Hu C, Ferchen K, Greis KD, Jiang X, Wei M, Qu L, Guan JL, He C, Yang J, Chen J. Recognition of RNA N (6)-methyladenosine by IGF2BP proteins enhances mRNA stability and translation. Nat Cell Biol. 2018;20(3):285-95. https://doi.org/10.1038/s41556-018-0045-z.

35. Del Rio M, Mollevi C, Bibeau F, Vie N, Selves J, Emile JF, Roger P, Gongora C, Robert J, Tubiana-Mathieu N, et al. Molecular subtypes of metastatic colorectal cancer are associated with patient response to irinotecan-based therapies. Eur J Cancer. 2017;76:68-75. https://doi.org/10.1016/j.ejca.2017.02.003.

36. Shen Y, Tong M, Liang Q, Guo Y, Sun HQ, Zheng W, Ao L, Guo Z, She F. Epigenomics alternations and dynamic transcriptional changes in responses to 5-fluorouracil stimulation reveal mechanisms of acquired drug resistance of colorectal cancer cells. Pharm J. 2018;18(1):23-8. https://doi.org/10.1038/ tpj.2016.91.

37. Tsuji S, Midorikawa Y, Takahashi T, Yagi K, Takayama T, Yoshida K, Sugiyama Y, Aburatani H. Potential responders to FOLFOX therapy for colorectal cancer by random forests analysis. Br J Cancer. 2012;106(1):126-32. https:// doi.org/10.1038/bjc.2011.505.

38. Fumagalli F, Noack J, Bergmann TJ, Cebollero E, Pisoni GB, Fasana E, Fregno I, Galli C, Loi M, Solda T, et al. Translocon component Sec62 acts in endoplasmic reticulum turnover during stress recovery. Nat Cell Biol. 2016; 18(11):1173-84. https://doi.org/10.1038/ncb3423.

39. Jung SJ, Kim JE, Reithinger JH, Kim H. The Sec62-Sec63 translocon facilitates translocation of the C-terminus of membrane proteins. J Cell Sci. 2014; 127(19):4270-8. https://doi.org/10.1242/jcs.153650.

40. Du J, Zhao Z, Zhao H, Liu D, Liu H, Chen J, Cheng B, Zhai X, Yin Z, Zhang Y, Ling C. Sec62 promotes early recurrence of hepatocellular carcinoma through activating integrinalpha/CAV1 signalling. Oncogenesis. 2019;8(12): 74. https://doi.org/10.1038/s41389-019-0183-6.

41. Takacs FZ, Radosa JC, Linxweiler M, Kasoha M, Bohle RM, Bochen F, Unger C, Solomayer EF, Schick B, Juhasz-Boss I. Identification of 3q oncogene SEC62 as a marker for distant metastasis and poor clinical outcome in invasive ductal breast cancer. Arch Gynecol Obstet. 2019;299(5):1405-13. https://doi.org/10.1007/s00404-019-05081-4.

42. Easwaran H, Tsai HC, Baylin SB. Cancer epigenetics: tumor heterogeneity, plasticity of stem-like states, and drug resistance. Mol Cell. 2014;54(5):71627. https://doi.org/10.1016/j.molcel.2014.05.015.

43. Takahashi H, Nakamura K, Usami A, Tsuruta T, Hashimura M, Matsumoto T, Saegusa M. Possible role of nuclear beta-catenin in resistance to preoperative chemoradiotherapy in locally advanced rectal cancer. Histopathology. 2017;71(2):227-37. https://doi.org/10.1111/his.13227.

44. Urushibara S, Tsubota T, Asai R, Azumi J, Ashida K, Fujiwara Y, Shiota G. WNT/beta-catenin signaling inhibitor IC-2 suppresses sphere formation and sensitizes colorectal cancer cells to 5-fluorouracil. Anticancer Res. 2017;37(8): 4085-91. https://doi.org/10.21873/anticanres.11795.

45. Dermani FK, Amini R, Saidijam M, Pourjafar M, Saki S, Najafi R. Zerumbone inhibits epithelial-mesenchymal transition and cancer stem cells properties by inhibiting the beta-catenin pathway through miR-200c. J Cell Physiol. 2018;233(12):9538-47. https://doi.org/10.1002/jcp.26874.

46. Shi H, Wei J, He C. Where, when, and how: context-dependent functions of RNA methylation writers, readers, and erasers. Mol Cell. 2019;74(4):640-50. https://doi.org/10.1016/.jmolcel.2019.04.025.

47. Li T, Hu PS, Zuo Z, Lin JF, Li X, Wu QN, Chen ZH, Zeng ZL, Wang F, Zheng J, Chen D, Li B, Kang TB, Xie D, Lin D, Ju HQ, Xu RH. METTL3 facilitates tumor progression via an $\mathrm{m}$ (6) A-IGF2BP2-dependent mechanism in colorectal carcinoma. Mol Cancer. 2019;18(1):112. https://doi.org/10.1186/s12943-019-1 038-7.

\section{Publisher's Note}

Springer Nature remains neutral with regard to jurisdictional claims in published maps and institutional affiliations.

Ready to submit your research? Choose BMC and benefit from:

- fast, convenient online submission

- thorough peer review by experienced researchers in your field

- rapid publication on acceptance

- support for research data, including large and complex data types

- gold Open Access which fosters wider collaboration and increased citations

- maximum visibility for your research: over $100 \mathrm{M}$ website views per year

At BMC, research is always in progress.

Learn more biomedcentral.com/submissions 